\title{
PLANNING AND RESOURCE CALCULATION OF A RESIDENTIAL BUILDING WITH DELAY ANALYSIS
}

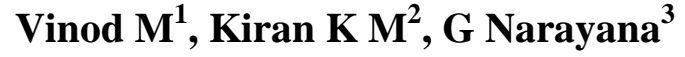 \\ ${ }^{1}$ Post Graduate Student, Department of Civil Department, S.J.C.I.T, Chickballapura, Karnataka, India \\ ${ }^{2}$ Assistant Professor, Department of Civil Department, S.J.C.I.T, Chickballapura, Karnataka, India \\ ${ }^{3}$ Professor \& Head of Department of Civil Engineering, S.J.C.I.T, Chickballapura, Karnataka, India
}

\begin{abstract}
In construction, for the timely and economical completion of project coming up with and planning became a vital a part of any project. a correct construction schedule will be used for various purpose. By exploitation construction schedule to predict project completion, contractors will alter crew size, shifts or instrumentality to hurry or slow the progress. It's a project slippery over its planned schedule and is taken into account as common downside in construction comes. tiny project will be managed with efficiency manually; whereas massive project aren't thus massive project will be handled by the utilization of laptop. Analysis ought to be in serious trouble the aim on creating right choices on time and value compensation claims. Many types of software system square measure on the market with the assistance of that project management will be done simply. massive quantities of various sorts of resources square measure needed for execution and also the risk is a lot of within the case of comes. thus coming up with and planning of activities for construction of massive project is crucial. The main of this study is to analyse the Project Management Techniques by planning varied construction activities, allocation of resources and resource levelling exploitation Microsoft Project and Microsoft stand out software system, personnel of every activities determined and allocation is completed exploitation software system for residential building.
\end{abstract}

Keywords: Planning, Resource Management, Delay Analysis.

\section{INTRODUCTION}

Construction industry plays an important role within the economic process of a rustic through the multiple effects of the opposite sectors of economy. Construction is defined as a creation, renovation, repair and demolition of immobile structures and alteration of natural topography. It is somewhat just like the process to satisfy the desired demand of homeowners like modification of arrange, specifications and resources within the project schedule, cost and quality. Due to the unique nature of construction project, knowledge gained in coming up with, scheduling and dominant construction method is seldom unfold. This results in value of in-efficiency that is being incurred as a requiring cost.

By taking the expenditure of construction industry, the Project Management profession became much valuable in order to create positive the project goes in an exceedingly right track to complete with success. The project management acts as a critical path in construction project, where it contains the information of coming up with, scheduling, controlling and implementing the things.

Developing good construction arrange is vital path in construction management. A plan acts as a basis for developing budget and schedule of the work.

A project is now thought of as a cluster of activates interrelated, which could embody a task of specialist and specialized work victimization latest information and a talented men out there to be order taken in most systematic manners. The" most systematic manner" involves adoption of techniques like CRITICAL PATH METHODOLOGY (CPM) or PROGRAM ANALYSIS and REVIEW TECHNIQUE (PERT) are applied to Project Management.

\section{STATEMENT OF THE PROBLEM}

In past, due to lack of data about the development management, improper planning has LED to project period overrun and value overrun. Where the project had undergone huge loss. So, proper coming up with and programing of the construction project with advanced technologies may be a necessary. In the earlier 50's the thought scientific coming up with programing was completely neglected within the construction filed till once the concept of CPM and irreverent created an effect.

So, meticulous care has to be taken within the project. Based on the project coming up with and programing the required things i.e. money, manpower, machinery should be procured for every and each activities within the schedule. If this process provides a right path, then the project will be on path as an alternative the project could face delay. Care should be taken in men and material acquisition in order to spot over of surplus men and areas of shortage of men. Finally our main concern is naturally to plan, schedule associated allocate men and procure materials in an optimum manner therefore as to complete the project on the regular date. 
Therefore, the main objective of this study is to complete the project on schedule date with the given budget work prescribed quality. If any unforeseen problems rose, the project schedule must be update and a new update schedule ought to be shaped.

\section{PROJECT MANAGEMENT}

The process of directing and bringing human and material resource into an efficient way of working throughout the life of a project by using advanced management technologies to achieve predetermined objectives., scope, cost, time and quality and participation satisfaction is involve in project management.

The objectives are settled up in the project management, which are to be fulfilled by implementing a serious set of operations subjected to resource constrains. Some of the potential disagreements included in these objectives with respect to scope, cost, time, and quality and also the disagreement imposed on manpower, material and financial resource. All these conflicts should be resolved by taking necessary tradeoffs or creating new alternatives.

The functions of project management generally include the following:

- The detailed description of scope, budgeting, scheduling, setting performance requirement and selecting project state holders are involved in the specification of project objective.

- Scheduling and planning property to maximize efficient resource utilization through procurement of labour, material and equipment.

- Implementation of various operations through a proper coordination and control of planning, design, estimating, contracting and construction in the process.

- Maintenance of good relations among the various participants for resolving conflicts.

- Effective communication development.

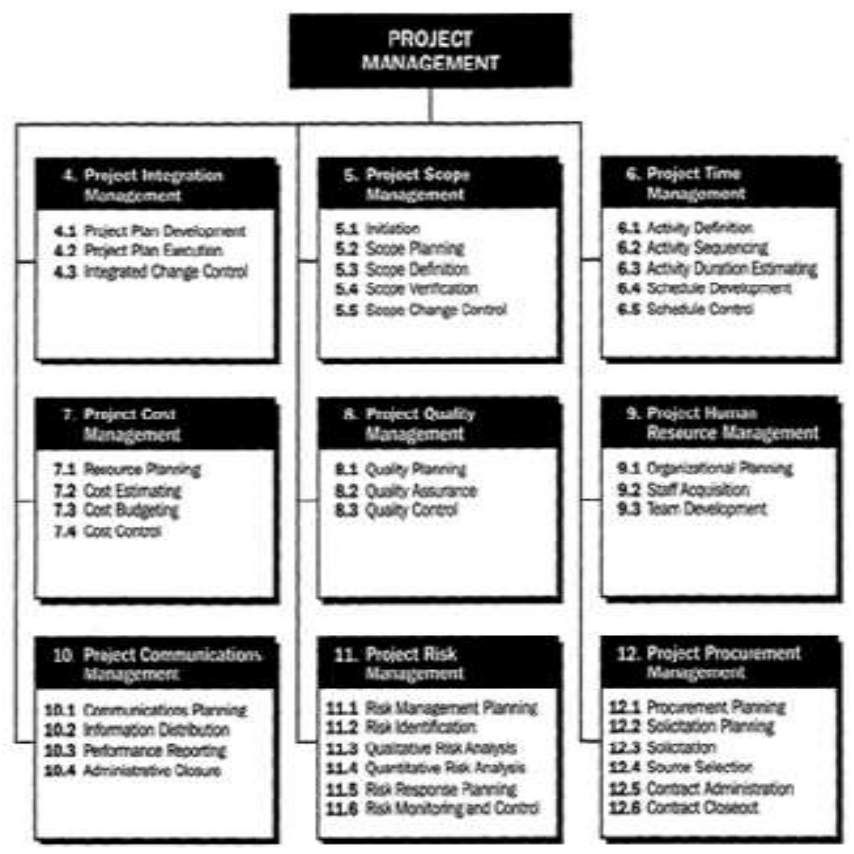

\subsection{Planning and Scheduling}

The process of describing a precise time bound plan of action for controlling various activities and resource to achieve specified goals and objectives is called planning. That is it is a process of developing a project plan which depicts the direction of the process to achieve the assigned goals.

Construction planning is most important fundamental and challenging part of the project, which involves the process of listing of all activities and tasks in a sequential order. Smart work is essential in this phase to avoid risk of delay and rework. Hence the planning need to be done necessarily, which involves project predetermination of required material, manpower, machinery, money etc.

Defining the project provides the most valuable info out there on the project at the first stages on the far side being needed for the initial go or no go call by management.

This document may service as

- A general information for different managers

- A statement of goal, project direction and problems and chance to be addressed by project.

Defining a project can provide a project document known as " project overview" that acts because the foundation half on that project activation are going to be based mostly.

\subsection{State the Problems}

The project manager should be ready for the many assignments travel from well rigorously thought of things to people who are nonchalantly outlined.

The project at its initial stage, yet to be outlined clearly printed in project summary. What is expected by when, by whom and with what resources.

\subsubsection{What is the Matter or Opportunity?}

A project management team is necessary at the time of critical want then a general management. The need arise from an indoor or external issues or state of affairs, that either threatens the organization. The need could arise from a replacement product, service, process or system, even for developing new marketing that involves many professionals across the organization.

\subsubsection{What is to be Done?}

Plan and conduct meeting this is necessary to jot down the goal of the project follows from stating the matter the necessity or chance. This statement should not mislead anyone for whom it's referred.

\subsubsection{Who is Accountable for the Project?}

In any company, the project managers acts as a soul for the project UN agency is the approved to issue a note to all or any the members who can be littered with project with the 
stating the project, name, objective and approximate start and ending dates of project. In the project, the person based on his designation should be employed and appointed for his job.

\subsubsection{When the Project should be Completed?}

This is the important info given however the project are often completed among the provided point in time. This considers not only the attention to the purpose that the project can have however additionally sets in motion of designing and budgeting activities with the subsequent thought of.

1. The water cooler imposed point in time

2. The planed and estimated point in time

\subsubsection{Identify Project Goals}

Each and each project has its own and specific major goals to be accomplished with many objectives that support the goal. The goal is the worldwide statement of purpose and direction towards which all objectives, work activities and task will be state to realize the project. Goal defines the final out comes with reference to the tip products or services.

\subsubsection{Listing the Objectives.}

Objects are the action adjusted on and most precise statements, where they are not actual works to be accomplished however sub goals that direct work actively.

Objectives represent the major components of the project known as milestone. Writing the objectives required a ton of follow and discipline objectives ought to be good for effective project coming up with good mean.

- Being specific in result which aims to reach

- Setup a measurable indicator of progress

- Make the objective capable of being assigned to somebody for completion

- Knowing what can realistically be reach among the budgeted limit of time on resource
- $\quad$ Stating when the objective are often achieved is among the period

\subsubsection{Determining Preliminary Resources}

Resource not only includes cash. Resource include men, materials, money and mechanical in the preliminary determination resources list are going to be like

- Manpower include however several, how, when and for however long

- Equipment include what, when and however long

- Money: direct value and indirect cost

\subsubsection{Identifying Assumption \&Amp; Risks}

The project idea should be realistic, wherever the product ought to beautifully sell a concept where you want to believe it and have enough confidence in its work. The assumption and risks related to each objective is that the step towards acknowledging your information at assumptions and risks involving with coming up with and terminations of project. Identifying the assumptions and risks helps you to go through the issues related to the exiting the project while not delays.

\subsection{Work Breakdowm Structure}

The concept of work breakdown structure is to create the project simply comprehendible and quickly perfect. WBS involves managing the project as a hierarchical decomposition of goal objectives, activities sub activities and work package. This hierarchical decomposition can goes on continued till the entire project is displayed as a network with known and non-overlapping activities. Each activity can be well outlined and planned with specific time period manageable, its time on cost estimate deliverable clearly understood and clearly completion responsibilities. As we found the WBS facilities the coming up with, budgeting, scheduling and management activities of project management and team.

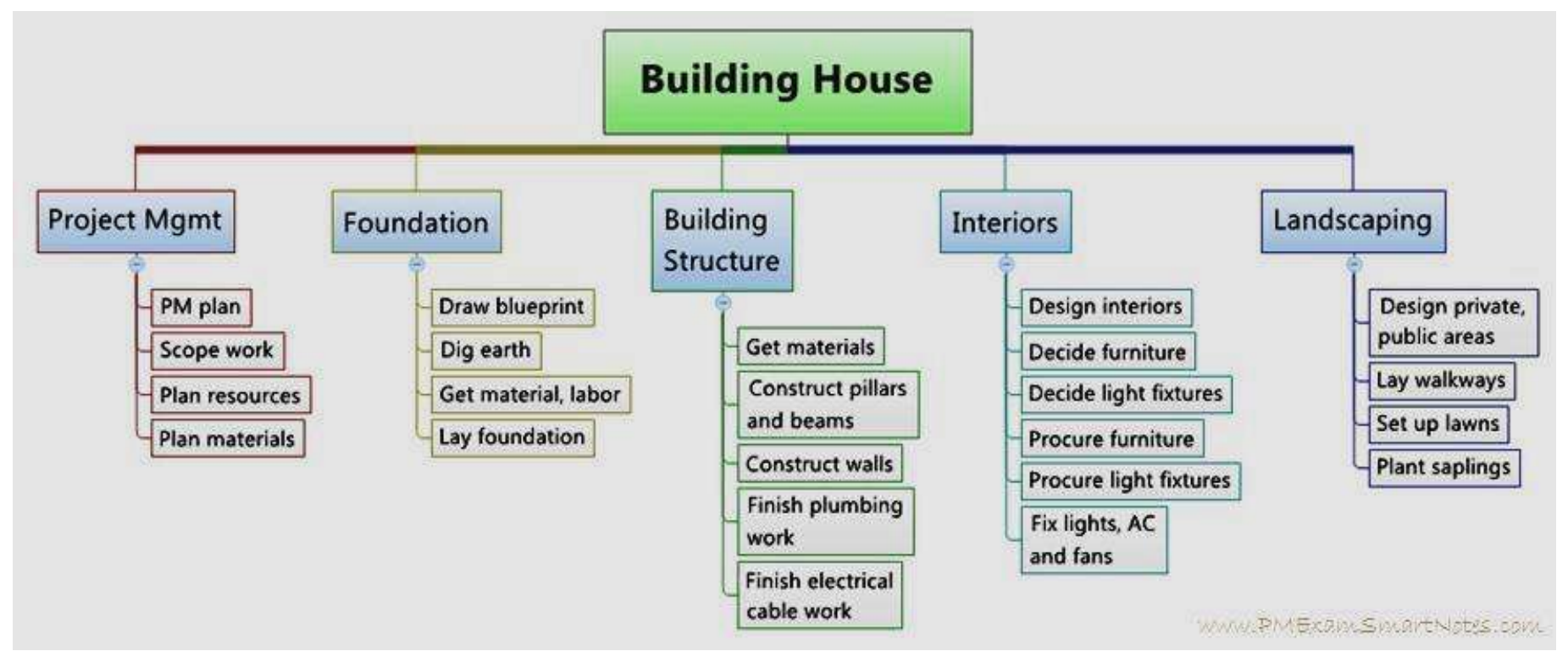

Fig 1.Sample of WBS for a Residential Building 


\section{RESOURCE PLANNING}

A resource is a physical quantity like money, manpower, material, machinery, time or space that is needed for carrying out a project. For efficient carrying over of project, the resources should be allotted as per the schedule and period. The main objective of an organization isn't to waste the recourses.

\subsection{Resource Allocation}

The feasibility of the network shall be check with reference to men, equipment and different resources of the website.

\subsection{Resource Leveling}

To obtain optimum uniform resource needs, the reallocation of the slack resource from non-critical path to critical activity path in order to get a discount of your time or shifting the activities among floats out there with them.

\subsection{Resource Schedule}

Based on the network development and information base of the project, the schedule of resource requirement is ready and regular.

\subsection{Man Power Coming Up With}

For each and each activity supported its information and period, manpower has to be assignment. This manpower shall be calculated from the commonplace information or from the past expertise on the quantity of days needed for completion of various activities.

\section{CASE STUDY DETAILS}

\begin{tabular}{|l|l|}
\hline PROJECT TITLE & $\begin{array}{l}\text { OZONE TOWN SERINA } \\
\text { DEVENAHALLI }\end{array}$ \\
\hline Location & Devanahalli, Bangalore \\
\hline Site Area & 4.56 acres \\
\hline Total number of blocks & 5 Blocks \\
\hline Total number of units & 320 Units \\
\hline Total number of floors & Basement+Ground+7 floors \\
\hline $\begin{array}{l}\text { Constructed area/plinth } \\
\text { area }\end{array}$ & $3,93,727$ sq. ft \\
\hline $\begin{array}{l}\text { Number of flats in every } \\
\text { floor }\end{array}$ & 8 Flats(3BHK + 2BHK) \\
\hline $\begin{array}{l}\text { Total number of flats in } \\
\text { every block }\end{array}$ & 64 \\
\hline Block consists & Residential Apartments \\
\hline $\begin{array}{l}\text { Overall project execution } \\
\text { Development Services Pvt } \\
\text { Ltd. }\end{array}$ \\
\hline Project consists & Residential Apartments \\
\hline $\begin{array}{l}\text { Zoning as per } \\
\text { corporation bye laws }\end{array}$ & Zone “C” \\
\hline Land used & Residential / Commercial \\
\hline
\end{tabular}

\subsection{Labour Productivity Chart}

Productivity chart is prepared by the senior coming up with engineers and a few old personnel's of the project supported the standards and in progress productivity rate. The quantity of labour needed for the project helps United States to estimate the men needed to the project through out there style drawings.

The duration of activities calculated based mostly on the productivity could vary on level of construction and machineries handiness. Thus, the productivity norms used in this project relies on the observations at site throughout the previous works undertaken by the corporate.

\subsubsection{Calculation}

The following section illustrates the quantities obtained for column reinforcement and column formwork for ground floor as per BOQ

\section{Slab Reinforcement}

Reinforcement quantity $=30910 \mathrm{~kg}$

Output per team: $400 \mathrm{~kg} / \mathrm{day}$. As per Table 5.7.1

Man power for an activity= amount/ (average quantity constant $*$ duration of task)

$=30910 /(400 * 17)=6$ man per day.

6 Bar benders and labour should be assigned.

\section{Slab Formwork}

Formwork quantity $=1170$ Sq. $\mathrm{m}$

In one day one carpenter and one mazdoor can work to supply twelve sq. $\mathrm{m} /$ day

Man power for an activity= amount/ (average quantity constant $*$ duration of task)

$=1170 /(12 * 17)=6$ man per day

6 Carpenter and helper ought to be assigned.

\section{Block Work}

Block work quantity $=1407$ Sq. $\mathrm{m}$

In one day one mason and one helper can work to supply fifteen sq. m/day

Man power for an activity= amount/ (average quantity constant $*$ duration of task)

$=1407 /\left(15^{*} 10\right)=10$ man per day

10 Mason and helper ought to be assigned.

\section{Internal Plastering}

Plastering quantity $=3592 \mathrm{Sq}$. $\mathrm{m}$

In one day one mason and one helper can work to supply ten sq. m/day

Man power for an activity= amount/ (average quantity constant $*$ duration of task) $=3592 /(10 * 40=8$ man per day

\section{DELAY ANALYSIS}

Delay is one of major problems occurring on the development project website. No plan is dead as it has is 
really planned. The construction projects are targeted to complete the project among the schedule time on budget with the considerable quality. When there are delays on the project website, it can cause negative effects such as increased value, loss of productivity and revenue and disputes between owners, consultant and contractors and it could additionally result in contract termination.

\section{Major Factors Inflicting Delay}

Based on the assorted studies the subsequent delay has been encountered.

- Slow preparation and approval of shop drawings

- Delay in payment to contractors

- Changes in style or if any design error

- Shortage of skilled labour

- Poor workman ship

- Change in orders by the costumers throughout contraction.

- $\quad$ Shortage of labour supply

- Ineffective planning and schedule

- Difficult in finance half payments to the contractors.

- Unforeseen ground conditions

- Variations of client

- Contractors' inefficiency

- Poor supervision and website management

- Slow coordination and seeking of approval from concerned authority.

\section{CONCLUSION}

The contract of construction was awarded by clients to the consultants and contractors to end the add twenty four months. In the baseline study the duration of the contract is 736 days. The duration of every activity was calculable supported the quantities through the drawings and from the information of the old personals of the project. The critical activities of the project are foundation, casting of floor slab, block work, external plastering, painting and doors. In spite of critical activities, there are some further activities wherever the project old difficulties in execution and delay in completion.

From the Delay Analysis an quantity of Rs eleven, 68,900/ has been incurred to the project which is associate further lost to the project and at the same time over shoots the budget allotted to the project. The main causes of delay within the project are each excusable and non-excusable delays, which are known by the incidence and expertise. The main delays were recorded and also the loss of productivity and price loss has been calculated.

\section{ACKNOWLEDGEMENTS}

I am thankful to Mr. Kiran K M and Dr.GNarayana for their guidance. I also thank department of civil engineering S J C institute of technology, chickallapura. And last but not the least my dear friends who have supported me to complete this project work.

\section{REFERENCES}

[1]. Samand M E Sepasgozar et al, "The Importance of New Technology for Delay Mitigation in Construction Projects". AJCEA 2015, vol 3, NO. 1, 15-20

[2]. Peter Stelth et al, "Projects Analysis through CPM (Critical Path Method)", School of doctorial studies.

[3]. Owolabi James D et al, "Causes and Effects of Delay on Project Construction Delivery Time". IJER April 2014, vol2,

[4]. Dr. SawsanRasheed Mohammed, "Construction Delay Analysis Using Daily Windows Technique". Journal of engineering 2013, vol 17.

[5]. Dr. Steen Lichtenberg, "how to avoid overruns and delay successfully”.IECE 2005

[6]. Olajide Timothy Ibironke, "Analysis of Non-Excusable Delay Factors Influencing Contractors". JCDC 2015.

[7]. K. L. Ravisankar et al, "Study on quantification of Delay Factors in Construction Industry". IJETAE 2014, Vol 4.

[8]. SaadHegazy, "Delay Analysis Methodology in UAE construction projects”. PM world journal 2012, vol 1.

\section{BIOGRAPHIES}

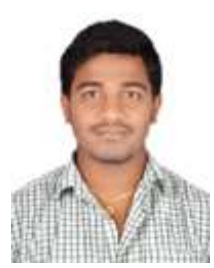

VINOD M, Pursuing Final Year M- tech in Infrastructure Engineering and mangement in SJC institute of Technology, Chickballapur.

vinod.nanni@gmail.com

MOBILE - 7204317515

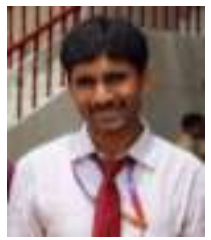

Mr. KIRAN K M, Assistant Professor, Department of Civil Engineering, SJC institute of Technology, Chickballapur. He has wide experience in teaching field for over 7 years and currently pursuing his Ph.D.

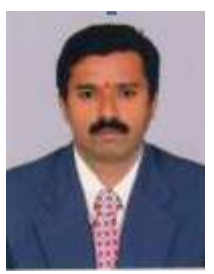

Dr.G.Narayana, Professor and Head of Civil Engineering Department, SJC institute of Technology, Chickballapur, have a wide experience in teaching and research in Structural Engineering field. He is also a Structural Designer and Consultant for many Projects. 